\title{
ACIDIZATION-II. THE DISSOLUTION OF CALCITE IN HYDROCHLORIC ACID
}

\author{
KASPER LUND $\dagger$ and H. S. FOGLER $\ddagger$ \\ Department of Chemical Engineering, The University of Michigan, Ann Arbor, MI 48 104, U.S.A. \\ and \\ C. C. McCUNE and J. W. AULT \\ Chevron Oil Field Research Company, La Habra, CA 90631, U.S.A.
}

(Received 6 May 1974; accepted 22 November 1974)

\begin{abstract}
The dissolution of calcite in hydrochloric acid was studied with the aid of a rotating disk system at 800 psig in the temperature range $-15 \cdot 6-25^{\circ} \mathrm{C}$. At $25^{\circ} \mathrm{C}$ the dissolution process is mass transfer limited even at high disk rotation speeds whereas at $-15.6^{\circ} \mathrm{C}$ both mass transfer and surface reaction rates limit the dissolution rate. The multicomponent coupled ionic diffusive fluxes of reactants and products were defined by using the gradient of the electrochemical potentials as driving forces for the diffusion. The activity coefficients used in calculating the multicomponent diffusivities of the diffusing species were estimated by Harned's rule. The concentration profiles of the ions in the boundary layer were then determined by numerically integrating the system of coupled convective diffusion equations. The effects of variable density, viscosity, and high mass fluxes on the fluid velocity in the boundary layer were taken into account. The rate of the surface reaction was found to be proportional to the 0.63 power of the surface hydrochloric acid concentration. Analysis of the experiments suggests that the absorption of hydrogen ion (described by a Freundlich adsorption isotherm) on the solid calcite surface and subsequent reaction of the adsorbed hydrogen ion with the solid calcite matrix is the reaction mechanism.
\end{abstract}

\section{INTRODUCTION}

The dissolution of calcite $\left(\mathrm{CaCO}_{3}\right)$ in acids is of interest to many fields of science, and the equilibrium relationships in the calcite-carbonic acid-water system have been studied extensively [1]. The dissolution rate of calcite in acids has been measured for such puposes as the formulation of antacids [2,3], the study of secondary changes in sedimentary deposits $[4,5,6]$, the $\mathrm{pH}$ of sea water [7-9], the neutralization of pickling acid $[10,11]$, the neutralization of acid mine drainage [12] and the acidizing of petroleum wells $[13,14]$.

Because it is a salt of a weak acid, calcite will dissolve in any stronger acid:

$$
\mathrm{CaCO}_{3}(\mathrm{~s})+2 \mathrm{H}^{+} \rightleftarrows \mathrm{Ca}^{++}+\mathrm{CO}_{2}(\mathrm{aq})+\mathrm{H}_{2} \mathrm{O} .
$$

The reaction product $\mathrm{CO}_{2}$ may participate in several other reactions $[1,15]$ :

$$
\mathrm{H}_{2} \mathrm{CO}_{3} \rightleftarrows \mathrm{CO}_{2}(\mathrm{aq})+\mathrm{H}_{2} \mathrm{O}
$$

and

$$
\mathrm{H}_{2} \mathrm{CO}_{3} \rightleftarrows \mathrm{H}^{+}+\mathrm{HCO}_{3}^{-} \rightleftarrows 2 \mathrm{H}^{+}+\mathrm{CO}_{3}{ }^{-} .
$$

The specific reaction rates for the hydration of $\mathrm{CO}_{2}$ and the dehydration of $\mathrm{H}_{2} \mathrm{CO}_{3}$ (Eq. (2)) are known [15] and are relatively small when compared with the specific rate for the ionic dissociation of carbonic acid (Eq. (3)). Consequently, the rate of the ionic dissociation can be considered infinitely fast with respect to these other two reactions.

The dissolution of calcite in acids is a rapid heterogeneous reaction, and the rate of dissolution will be limited both

†Presently at Norsk Hydro a.s, Bygdøy Allé 2, Oslo, Norway.

$¥$ To whom correspondence should be addressed. by the kinetics of the reaction at the solid-liquid interface and by the mass transfer of reactants and/or products through the fluid boundary layer. When calcite is dissolved by a weak acid, the reactants and products will form a buffer system in the boundary layer, which may significantly affect the dissolution rate. The mechanism of calcite dissolution by aqueous $\mathrm{CO}_{2}$ has been studied by several investigators with widely different results. The dissolution has been proposed to be controlled by the diffusion of acid to the solid-liquid interface, the hydration rate of $\mathrm{CO}_{2}$ in the boundary layer [16], the kinetic rate on the surface [17] and by diffusion of reaction products away from the surface[4].

When calcite is dissolved in a strong acid such as hydrochloric acid, the problem formulation changes markedly. The dissociation of the product, carbonic acid, will be suppressed by the presence of the strong acid (as long as its concentration is greater than $10^{-6}$ gmoles/liter); furthermore, the reaction given by $\mathrm{Eq}$. (1) may be considered. irreversible. The dissolution will therefore only be limited by diffusion of acid to the calcite surface and/or the reaction at the solid-liquid interface. At low pressures (the order of $1 \mathrm{~atm}$ ) gaseous $\mathrm{CO}_{2}$ will be released at the solid-liquid interface affecting the hydrodynamics and thus the dissolution rate. The extreme pressure dependence of the calcite dissolution in strong acids has not always been fully understood by investigators in petroleum production. For example [18], in an evaluation of the suitability of some surfactants for lowering the dissolution rate of calcite, a calcite crystal was rotated in a beaker filled with $15 \mathrm{wt} \% \mathrm{HCl}$ at $25^{\circ} \mathrm{C}$ and $1 \mathrm{~atm}$. In this experiment the effect of the surfactant may just be to change the surface tension and thereby the size of the $\mathrm{CO}_{2}$ bubble released. This effect will be absent at reservoir conditions. 
The rate of dissolution of calcite with hydrocloric acid in flow systems has also been measured at higher pressures $[14,19,20]$. In one study [19] a $15 \mathrm{wt} \%$ hydrochloric acid was forced through a limestone fracture at different flow velocities and the measured dissolution rates were fitted to an empirical reaction rate expression. The rate was found to vary with the $\mathrm{HCl}$ fluid velocity to the 0.8 power.

In two other investigations $[14,20]$ hydrochloric acid flowed between two parallel plates of which one was limestone. The velocity profile of the acid was fully developed before it reached the limestone plate and a back pressure of $1100 \mathrm{psi}$ was applied on the acid exit stream. The convective diffusion equation combined with a power law model for the kinetic rate at the solid-liquid interface was solved for the extent of acid consumption at the exit. The analysis showed the following reaction rate law to apply at $70^{\circ} \mathrm{F}$ :

$$
-r_{\mathrm{HCl}}=7.00 \times 10^{-6}\left(\gamma C_{\mathrm{HCl}}\right)^{0.2}, \text { gmoles } \mathrm{HCl} / \mathrm{cm}^{2} / \mathrm{sec}
$$

where

$$
\gamma=\text { mean activity coefficient of hydrochloric acid }
$$

$C_{\mathrm{HCl}}=$ concentration of $\mathrm{CCl}$ at the solid-liquid interface, gmoles/liter.

Several objections may be raised to the methods used in the data analysis. The effect of the other ions on the $\mathrm{H}^{+}$ mass transport was neglected although their influence may be quite large. The activity gradient of $\mathrm{HCl}$ was selected as the driving force for the diffusion, but unfortunately the significant effect of the other ions on the activity of $\mathrm{HCl}$ was not considered.

Preliminary dissolution rate experiments with calcite in hydrochloric acid were performed in a rotating disk apparatus [21,22]. Marble (calcite) disks of $2^{\prime \prime}$ diameter were dissolved while being rotated in hydrochloric acid (1 gmole/liter) at $25^{\circ} \mathrm{C}$ under a nitrogen pressure of $800 \mathrm{psig}$. It was found that application of this $\mathrm{N}_{2}$-pressure suppresses any gaseous $\mathrm{CO}_{2}$ evolution from the dissolving marble disk (either non-rotating or rotating). Mass transport to a rotating disk with an infinite surface reaction rate is proportional to the square root of the disk rotation speed $\left(\omega^{1 / 2}\right)$. In Fig. 1 the measured dissolution rates are plotted as a function of $\omega^{1 / 2}$. The straight line represents the fully mass transfer controlled dissolution rate with a diffusivity of $3.97 \times 10^{-5} \mathrm{~cm}^{2} / \mathrm{sec}$. We note that at these conditions the dissolution of calcite is nearly completely mass transfer limited. The surface reaction rate laws reported by the previous investigations $[14,20]$ (Eq. 4) do not agree with our experimental observations. For example, the dissolution rate of $9.4 \times 10^{-6}$ gmoles $\mathrm{HCl} / \mathrm{cm}^{2} / \mathrm{sec}$ (measured at $500 \mathrm{rpm}, 25^{\circ} \mathrm{C}$, and $1 \mathrm{~N} \mathrm{HCl}$ ) is nearly completely limited by mass transfer resistance. Therefore the $\mathrm{HCl}$ concentration at the solid-liquid interface, $C_{s}$, will be much smaller than the bulk acid concentration, $C_{b}$, of 1 gmole/liter (i.e. $C_{s}<<C_{b}$ ). Even with a surface concentration of 1 gmole/liter, the rate calculated from the rate law given by $\mathrm{Eq}$. (4) $\left[-r_{a}=7 \times 10^{-6}\right.$ gmole $\left.\mathrm{HCl} / \mathrm{cm}^{2} / \mathrm{sec}\right]$ is less than our meas-

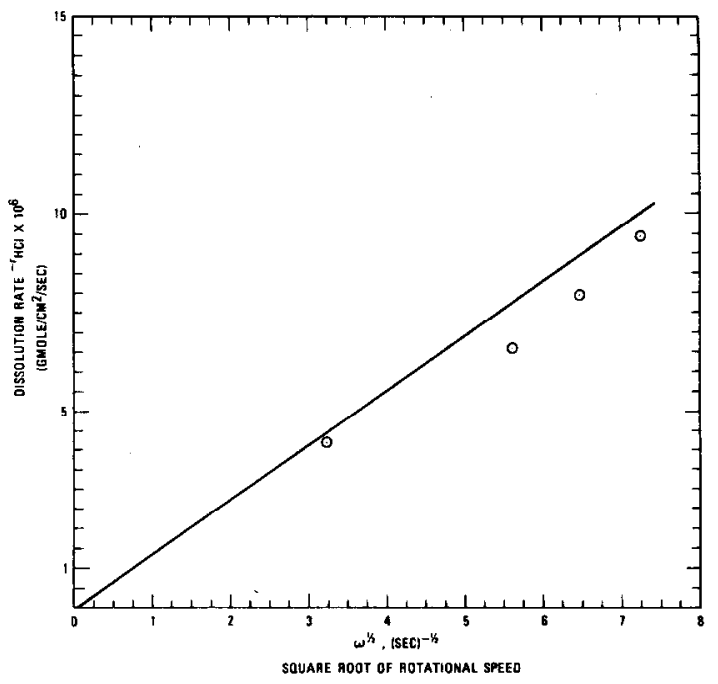

Fig. 1. Dissolution rate of calcite as a function of rotating speed for $1 \mathrm{~N} \mathrm{HCl}$ at $25^{\circ} \mathrm{C}$.

ured dissolution rate at a bulk concentration of 1 gmole/liter.

Since inconsistencies do exist in reported rates, we decided to investigate the reaction rate in detail by using the rotating disk apparatus. In order to find the functionality of the surface reaction rate, the concentration of $\mathrm{HCl}$ at the solid surface $C_{s}$ must be determined by solving the convective diffusion equations describing the mass fluxes. For the calculated value of $C_{s}$ to be accurate, the mass transfer resistance should be as small as possible. The preliminary calcite rate data at $25^{\circ} \mathrm{C}$ (Fig. 1) show the dissolution to be nearly completely mass transfer limited even at the maximum rpm of the rotating disk equipment. Owing to the significant differences in the diffusion and reaction activation energies, large changes in the ratio of the surface reaction resistance to the mass transfer resistance can be accomplished easily by lowering the temperature of the system. Consequently, a series of dissolution rate experiments were performed in the temperature range between $-15.6^{\circ} \mathrm{C}$ and $1{ }^{\circ} \mathrm{C}$. The ionic strength of the hydrochloric acid used for the $-15 \cdot 6^{\circ} \mathrm{C}$ experiments was made-up to approximately 5 gmoles/liter by addition of sodium chloride. The boundary layer may therefore contain the ions: $\mathrm{H}^{+}, \mathrm{Ca}^{++}$, $\mathrm{Na}^{+}$and $\mathrm{Cl}^{-}$.

\section{THEORETICAL ANALYSIS}

Formulation of the convective diffusion equations

The dissolution of a solid calcite disk rotating in hydrochloric acid is controlled by a mass transfer resistance and by a reaction rate resistance in series. Owing to the high flux rates, concentrated solutions, and ionic diffusion the calculation of the mass transfer resistance becomes quite involved. The high mass flux rates will change the ideal boundary condition at the solid-liquid interface from zero normal velocity to a finite velocity. With concentrated acid solutions (up to 9 gmoles $\mathrm{HCl} / \mathrm{l})$ large concentration gradients exist, causing the viscosity and density to vary in the laminar boundary layer and thereby affecting the velocity profile. The 
diffusion of the three ions $\mathrm{H}^{+}, \mathrm{Ca}^{++}$and $\mathrm{Cl}^{-}$(four ions when $\mathrm{Na}^{+}$is present) in the boundary layer will produce an electrical potential field. This field will couple the diffusive fluxes of the ions and may be strong enough to move an ion against its concentration gradient.

In a rotating disk, the boundary layer is of uniform thickness across the disk surface and the concentrations of the diffusing species are a function only of the distance, $x$, from the disk surfaces [22]. A mass balance on species $i$ being transported to or from the disk surface gives:

$$
\frac{\mathrm{d} m_{i}}{\mathrm{~d} x}+\rho V_{x} \frac{\mathrm{d}}{\mathrm{d} x}\left(\rho_{i} / \rho\right)=0 ; \quad i=1, \ldots, n
$$

The mass balance may also be expressed in molar quantities:

$$
\frac{\mathrm{d} J_{i}}{\mathrm{~d} x}+V_{x}\left(\frac{\mathrm{d} \tilde{C}_{i}}{\mathrm{~d} x}-\tilde{C}_{i} \frac{\mathrm{d} \ln \rho}{\mathrm{d} x}\right)=0 ; \quad i=1, \ldots, n .
$$

Since ions are diffusing, the mass transport will be coupled with electrical forces and the flux of each electrolyte may simply be expressed as linear combination of all concentration gradients:

$$
J_{i}=-\sum_{i=1}^{n} D_{i j} \frac{\mathrm{d} \tilde{C}_{j}}{\mathrm{~d} x} ; \quad i, j=1, \ldots, n .
$$

$D_{i j}$ is the multicomponent diffusion coefficient, $\mathrm{cm}^{2} / \mathrm{sec}$.

We now choose as a basis the conditions present at the solid-liquid interface (indicated by subscript $s$ ) to put Eq. (6) in dimensionless form. Defining $\theta$ as the dimensionless axial distance and $H(\theta)$ as the dimensionless axial velocity,

$$
\theta=\left(\frac{\omega}{\nu_{s}}\right)^{1 / 2}\left(\frac{\nu_{s}}{D_{s}}\right)^{1 / 3} x
$$

and

$$
V_{x}=\sqrt{\nu_{s} \omega} S c_{s}^{-2 / 3} H(\theta)
$$

and combining Eqs. (6-8) we find:

$$
\begin{aligned}
\sum_{i=1}^{n} \alpha_{i j} \frac{\mathrm{d}^{2} \tilde{C}_{i}}{\mathrm{~d} \theta^{2}}=H\left(\frac{\mathrm{d} \tilde{C}_{i}}{\mathrm{~d} \theta}-\tilde{C}_{i} \frac{\mathrm{d} \ln \rho}{\mathrm{d} \theta}\right) \\
-\sum_{j=1}^{n} \frac{\mathrm{d} \alpha_{i j}}{\mathrm{~d} \theta} \cdot \frac{\mathrm{d} \tilde{C}_{j}}{\mathrm{~d} \theta} ; i=1, \ldots, n .
\end{aligned}
$$

For a disk rotating in a fluid of constant properties and where the fluxes are small the dimensionless axial velocity[23] can be expressed by a polynomial in $\theta$ :

$$
\begin{aligned}
H(\theta)= & -0.51023 \theta^{2}+0.33333 \theta^{3} S c^{-1 / 3} \\
& -0.10265 \theta^{4} S c^{-2 / 3}+0.013 \theta^{5} / S c
\end{aligned}
$$

In real systems where there are spatial variations in the density and viscosity of the fluid and where an interfacial velocity does exist, it has been shown[24] that the axial velocity may be corrected by multiplying the velocity by the Schuh correction factor, Sch, to the half power:

$$
\operatorname{Sch}=\left(\frac{\mu_{b} \rho_{b}}{\mu_{s} \rho_{s}}\right)
$$

where $\mu$ is the viscosity of the solution $(\mathrm{g} / \mathrm{cm} / \mathrm{sec})$ and the subscripts $s$ and $b$ refer to the properties being evaluated at the disk surface and the bulk solution respectively. When the diffusive fluxes are large, they contribute to the convective velocity. At the disk surface the axial velocity, $V_{s}$, is finite and given by:

$$
V_{s}=\left(\sum_{i=0}^{n} \mathbf{n}_{i}\right) / \rho_{s}
$$

where $\mathbf{n}_{i}$ is the mass flux of species $i$ based on a fixed (stationary) reference frame, $\mathrm{g} / \mathrm{cm}^{2} / \mathrm{sec}$. The individual fluxes at the solid-liquid interface are defined by the stoichiometry of the heterogeneous reaction (Eq. 1) and may be expressed in terms of the hydrochloric acid flux.

$$
\begin{aligned}
& \mathbf{n}_{\mathrm{CaCl}_{2}}=-\frac{110.99}{2 \times 36.46} \mathbf{n}_{\mathrm{HCl}}=-1.5221 \mathbf{n}_{\mathrm{HCl}} \\
& \mathbf{n}_{\mathrm{CO}_{2}}=-\frac{44.00}{2 \times 36.46} \mathbf{n}_{\mathrm{HCl}}=-0.6036 \mathbf{n}_{\mathrm{HCl}} \\
& \mathbf{n}_{\mathrm{H}_{2} \mathrm{O}}=-\frac{18.00}{2 \times 36.46} \mathbf{n}_{\mathrm{HCl}}=-0.2469 \mathbf{n}_{\mathrm{HCl}} \\
& \mathbf{n}_{\mathrm{NaCl}}=0 .
\end{aligned}
$$

Then the mass average axial velocity at the solid-liquid interface becomes:

$$
V_{s}=-1 \cdot 3726 \mathbf{n}_{\mathrm{HCl}} / \rho_{s}=-50 \cdot 046 N_{\mathrm{HCl}} / \rho_{\mathrm{s}}
$$

where $N_{\mathrm{HCl}}$ is the molar flux of $\mathrm{HCl}$ based on a fixed reference frame, gmoles $/ \mathrm{cm}^{2} / \mathrm{sec}$.

The dimensionless velocity $H$ may be corrected [24] for nonzero axial velocity at the surface simply by adding $V_{\mathrm{s}}$ in a dimensionless form, $H_{s}$.

$$
H_{s}=-50.046 N_{\mathrm{HCl}} S c_{s}^{2 / 3} /\left(\rho_{\mathrm{s}} \sqrt{\nu_{s} \omega}\right)
$$

to $H$, i.e.

$$
\begin{aligned}
H= & H_{s}+\left(\frac{\mu_{b} \rho_{b}}{\mu_{s} \rho_{s}}\right)^{1 / 2}\left(-0.51023 \theta^{2}+0.33333 \theta S c_{s}^{-1 / 3}\right. \\
& \left.-0.10265 \theta^{4} S c_{s}^{-2 / 3}+0.013 \theta^{5} / S c_{s}\right)
\end{aligned}
$$

This approximation results in an error of less than $6 \%$ when the viscosity changes by a factor of 10 or less. Even under these conditions of high mass fluxes and variable properties the axial velocity is only a function of the axial distance; therefore the mass transfer rate to the disk surface will still have the property of being uniform across the disk surface. The boundary conditions, which together with the differential equations (Eq. 9) define the dissolution process, are given by the concentration of the electrolytes in the bulk acid solution, $\left(\tilde{C}_{i}\right)_{b}$, and by the fluxes at the solid-liquid interface, $N_{1}$. The concentration gradients at the solid-liquid interface may be computed from $N_{i}$ by noting that the fluxes relative to the mass-average reference frame, $J_{i}$, are given by:

$$
\left(J_{i}\right)_{s}=N_{i}+50 \cdot 046\left(\tilde{C}_{i} N_{\mathrm{HCl}} / \rho\right)_{s} ; \quad i=1, \ldots, n
$$

where: $N_{\mathrm{CaCl}_{2}}=-0.5 N_{\mathrm{HCl}}, N_{\mathrm{NaCl}}=0$, and $N_{\mathrm{HCl}}$ is measured by experiment. 
Then the application of the dimensionless form of Eq. (7) allows the determination of the concentration gradients at $\theta=0$ :

$$
\sum_{j=1}^{n}\left(\alpha_{i j} \frac{\mathrm{d} \tilde{C}_{j}}{\mathrm{~d} \theta}\right)_{s}=-\left(\frac{J_{i} S c^{2 / 3}}{\sqrt{\nu \omega}}\right)_{s} ; i=1, \ldots, n
$$

Infinitely far away from the disk surface the boundary conditions are

$$
\tilde{C}_{i}=\left(\tilde{C}_{i}\right)_{b} ; \quad i=1, \ldots, n .
$$

To solve this set of coupled differential equations with their associated auxiliary conditions, we need to know the values of the multicomponent diffusion coefficients, the density, and the viscosity as functions of the concentrations of the species present in the solution. Whereas the latter two properties may be estimated with sufficient accuracy by assuming the contributions of the individual species to be additive, this is not the case for the diffusivities.

\section{ESTIMATION OF THE MULTICOMPONENT DIFHUSIVITIES}

Ionic diffusion distinguishes itself from ordinary diffusion even at low ion concentrations since the ionic soiution is non-ideal and the fluxes and the diffusing ions are coupled by electrical forces. A rigorous set of equations describing the ionic transport process [25-30] may be derived with the aid of irreversible thermodynamics, and although these equations generally cannot be applied directly, due to lack of data, they do point out the manner in which an approximate set of multicomponent diffusivities, $D_{i j}$, may be estimated with little loss of accuracy. This set of $D_{i j}$ 's may then be estimated from binary thermodynamic data. An experimental test of the approximations for the ternary system $\mathrm{NaCl}-\mathrm{KCl}-\mathrm{H}_{2} \mathrm{O}$ at an ionic strength ranging between 0.5 and 3.0 molar shows the estimated $D_{i j}$ 's to deviate from the experimentally measured ones in the range of $4-20 \%$. The details on the application of the molar flux equations for ionic diffusion to the calcite- $\mathrm{HCl}$ is given by Lund [31]. In the analysis we assume that the reaction products, $\mathrm{CO}_{2}$ and $\mathrm{H}_{2} \mathrm{CO}_{3}$, do not interact in any significant way with the diffusive fluxes and forces.

The chemical formula of the electrolytes and the way they dissociate may be expressed in general terms as:

$$
C_{r_{i c}} A_{r_{i a}} \rightleftarrows r_{i c} C_{i}^{z_{i}}+r_{i a} A_{n+1}^{z_{n+1}} ; \quad i=1, \ldots, n
$$

where

$C_{i}=$ cation $i$ with charge $z_{i}$

$r_{i c}=$ number of cations $i$ in one formula unit of electrolyte $i$

$A_{n+1}=$ common anion of charge $z_{n+1}$

$r_{i a}=$ number of anions in one formula unit of electrolyte $i$

$n=$ number of electrolytes in the aqueous solution (the subscript zero indicates the solvent, water).

(For example, if $\mathrm{CaCl}_{2}$ is the second electrolyte in an aqueous solution of $\mathrm{HCl}$ and $\mathrm{CaCl}_{2}$ then: $n=2 ; C_{2}=$ $\mathrm{Ca}^{++} ; A_{3}=\mathrm{Cl}^{-} ; r_{2 c}=1 ; r_{2 a}=2 ; z_{2}=2 ; z_{3}=1$ ). The flux expressions in terms of the electrolytes, the relationship between the fluxes and driving forces are [31]:

$$
\left(J_{i}\right)_{0}=-\sum_{j=1}^{n} L_{i j} \frac{\mathrm{d} \Psi_{j}}{\mathrm{~d} x} ; \quad i=1, \ldots, n
$$

where;

$\left(J_{1}\right)_{0}=$ molar flux of electrolyte $i$ relative to the solventfixed reference frame

$L_{i j}=$ thermodynamic diffusion coefficient

$\Psi_{j}=$ chemical potential of electrolyte $j$.

The chemical potential $\Psi_{j}$ of the electrolyte $j$ is given by:

$$
\Psi_{j}=\Psi_{j}^{0}+R T \ln a_{j}
$$

and the thermodynamic coefficients are related to the limiting equivalent electrical conductance of ion $i \Lambda_{i}^{\circ}$, the number of formula units of the cations and anions, the ion charges and Faraday's constant

$$
\frac{L_{i j}}{\Omega}=\frac{W_{i} \Lambda_{i}^{0}\left(\delta_{i j} \Lambda^{0}-W_{j} \Lambda_{j}^{0}\right)}{10^{3} r_{i c} r_{i c} z_{i} z_{j} F^{2} \Lambda^{0}} ; \quad i, j=1, \ldots, n
$$

where: the equivalent fraction $W_{i}$ is the ratio of the equivalent strength of the ion $j, \Omega_{j}$, to the total number of equivalents in the solution, $\Omega$.

$$
W_{j}=\Omega_{j} / \Omega
$$

with

$$
\begin{aligned}
& \Omega_{j}=r_{j c} z_{j} \tilde{C}_{j} ; j=1, \ldots, n \\
& \Omega=\sum_{j=1}^{n} \Omega_{j} .
\end{aligned}
$$

and

$$
\Lambda^{0}=\sum_{i=1}^{n+1} W_{i} \Lambda_{i}^{0} \text { and } W_{n+1}=1
$$

Instead of the electrolytes being expressed in terms of linear combinations of the chemical potential gradients (Eq. 21) they may be expressed in terms of the more usual concentration gradients of the electrolytes

$$
\left(J_{i}\right)_{0}=-\sum_{j=1}^{n} D_{i j}^{0} \frac{\mathrm{d} \tilde{C}_{j}}{\mathrm{~d} x} ; \quad i=1, \ldots, n
$$

$D_{i j}^{0}$ is the diffusivity based on a solvent-fixed reference frame.

The diffusion coefficients $D_{i j}^{0}$ are related to the thermodynamic diffusion coefficients $L_{i j}$ by:

$$
\left.D_{i j}^{\mathbf{0}}=\sum_{k=1}^{n} L_{i k} \frac{\partial \Psi_{k}}{\partial \tilde{C}_{j}} ; \quad i, j=1, \ldots, n\right)
$$

with

$$
\begin{aligned}
\frac{\partial \Psi_{k}}{\partial \tilde{C}_{j}}= & \frac{R T}{\tilde{C}_{j}}\left(r_{k c} \delta_{k j}+r_{k a} W_{j}+\left(r_{k c}+r_{k a}\right)\right. \\
& \left.\times \tilde{C}_{j} \frac{\partial \ln y_{k}}{\partial \tilde{C}_{j}}\right) ; \quad k, j=1, \ldots, n .
\end{aligned}
$$


Although the solvent-fixed reference frame is advantageous in defining the fluxes, the mass-fixed reference frame is more suitable for the final analysis in modeling the dissolution. Letting the fluxes refer to a mass-fixed reference frame,

$$
J_{i}=-\sum_{j=1}^{n} D_{i j} \frac{\partial \bar{C}_{j}}{\partial x} ; \quad i=1, \ldots, n
$$

it may be shown that the diffusivities in the two reference frames are connected through (Lund [31]):

$$
D_{i j}=D_{i j}^{0}-\frac{\rho_{i}}{\rho} \sum_{k=1}^{n} D_{k j}^{0} \frac{\tilde{M}_{k}}{\tilde{M}_{i}} ; \quad i, j=1, \ldots, n .
$$

In most of the runs at $-15.6^{\circ} \mathrm{C}$ and some of the $1^{\circ} \mathrm{C}$ experiments the acid solution contained $\mathrm{NaCl}$. The resulting quaternary ionic system $\mathrm{HCl}-\mathrm{CaCl}_{2}-\mathrm{NaCl}-\mathrm{H}_{2} \mathrm{O}$ is more complicated to analyze than the ternary system $\mathrm{HCl}-\mathrm{CaCl}_{2}-\mathrm{H}_{2} \mathrm{O}$ and we chose to assume [27, 29]:

$$
\frac{\partial \ln y_{k}}{\partial C_{j}}=0 ; \quad k, j=1,2,3
$$

This approximation was also investigated for the $\mathrm{NaCl}-\mathrm{KCl}-\mathrm{H}_{2} \mathrm{O}$ system [27] and the computed $D_{i j}$ were found to deviate $10-20 \%$ from the experimentally measured $D_{i j}$.

Then the expression for the solvent-fixed diffusivities (Eq. 26) simplifies to [28]

$$
D_{i j}^{0}=\frac{R T}{F^{2}} \frac{r_{j a} \Lambda_{i}^{0}}{r_{i a} \Lambda^{0}}\left(\delta_{i j} \frac{\Lambda^{0}}{z_{i}}-W_{i}\left(\frac{\Lambda_{j}^{0}}{z_{i}}+\frac{\Lambda_{n+1}^{0}}{z_{n+1}}\right)\right)
$$

For the ternary system, excellent estimates of the activity coefficients can be determined from activity and osmotic coefficients for binary systems by applying Harned's rule [25, 32-34]. Estimates of $\partial \ln y_{i} / \partial \tilde{C}_{i}$ may be computed; and then by applying Eqs. (26), (29) and (31), excellent estimates of the multicomponent diffusivities can be found at any concentration of $\mathrm{HCl}$ and $\mathrm{CaCl}_{2}$ in the aqueous solution.

\section{EXPERIMENTAL}

Calcite in the form of white marble from West Rutland, Vermont (Ward's Natural Science Establishment, Inc., Rochester, NY), was used in this study. Microscopic examination of a thin section identified the mineral as a coarsely crystalline calcite with a maximum crystal size of about $0.2 \mathrm{~cm}$. The calcite was shown by $\mathrm{X}$-ray diffraction analysis and chemical analysis to be pure.

The description of the rotating disk apparatus and the procedure used in performing a dissolution rate experiment have been given previously [21, 22]. For the dissolution rate experiments at $-15.6^{\circ} \mathrm{C}$ and $1^{\circ} \mathrm{C}$ the apparatus was placed in a $4^{\prime} \times 4^{\prime} \times 4^{\prime}$ refrigeration unit which was

†For ternary diffusion the ions $\mathrm{H}^{+}, \mathrm{Ca}^{++}, \mathrm{Cl}^{-}$are numbered 1,2 and 3; for quaternary diffusion the ions $\mathrm{H}^{+}, \mathrm{Ca}^{++}, \mathrm{Na}^{+}, \mathrm{Cl}^{-}$are numbered $1,2,3$ and 4 respectively. maintained at a temperature $2-3^{\circ} \mathrm{C}$ below the desired temperature of the experiment. The heating control circuit of the rotating disk apparatus was then used to maintain the temperature of the reacting system at the desired level within $\pm 0.5^{\circ} \mathrm{C}$. A nitrogen pressure of 800 psig was applied to the reacting system. During the course of an experimental run, 5-6 samples of acid were withdrawn from the reactor and analyzed (for calcium ion content) with a Perkin Elmer Model 303 atomic absorption spectrophotometer. From the sample analysis the hydrochloric acid concentration could be calculated at any time by

$$
\bar{C}_{\mathrm{HCl}}=\bar{C}_{\mathrm{HCl}}^{0}-2 \bar{C}_{\mathrm{Ca}^{++}}
$$

where $\tilde{C}_{\mathrm{HCl}}$ is the $\mathrm{HCl}$ concentration at the time of sampling, $\tilde{C}_{\mathrm{HCl}}^{\circ}$ is the initial acid concentration, and $\tilde{C}_{\mathrm{Ca}^{++}}$ is the calcium ion concentration of the liquid sample. To minimize the change in surface area resulting from uneven attack by the acid on the disk face, the reaction was allowed to proceed only for short periods of time. Approximately $2-6 \%$ of the acid was spent and a solid layer $0.01-0.1 \mathrm{~cm}$ thick was dissolved from the disk surface during an experiment. Since the rate of dissolution did vary slightly with time (because of increasing roughness of the disk surface as the experiment progressed), the initial rate of dissolution was used in our analysis. For the rotating disk apparatus used in this study it may be shown that the mass transfer rate will attain its full value within 1 second after start-up [35].

Large density differences (up to 15\%) may exist in the liquid boundary layer adjacent to the disk surface due to the high rate of dissolution of calcite and the strong hydrochloric acid solutions used. The density of the solution at the solid-liquid interface will be larger than the density of the bulk solution, and mass transfer by natural convection may possibly be important for the dissolution process. However, the contribution of natural convection to the mass transport can be neglected under the experimental conditions given here [31].

\section{DISCUSSION \\ Analysis of the dissolution data \\ The system of second order non-linear ordinary} differential equations (Eq. 9) with appropriate boundary conditions were solved for each rotating disk experiment completed. The calculated ionic concentration profiles for $\mathrm{H}^{+}, \mathrm{Ca}^{++}, \mathrm{Na}^{+}$and $\mathrm{Cl}^{-}$are shown in Figs. 2 and 3 for representative experiments performed at $1^{\circ} \mathrm{C}$ and $-15 \cdot 6^{\circ} \mathrm{C}$ respectively $\dagger$. In both experiments the ionic strength and chloride ion concentration at the solid-liquid interface were larger than their bulk solution values. The relative high concentration of $\mathrm{Ca}^{++}$at the calcite surface is due to the large value of the ratio of the limiting equivalent conductivity of $\mathrm{H}^{+}$to the limiting equivalent conductivity of $\mathrm{Ca}^{++}\left(7.1\right.$ at $\left.1^{\circ} \mathrm{C}\right)$. The chloride ion does not enter into the reaction stoichiometry and the finite value of the chloride ion concentration gradient results from the coupling (by coulombic forces) between the chloride ion and the other ions. 


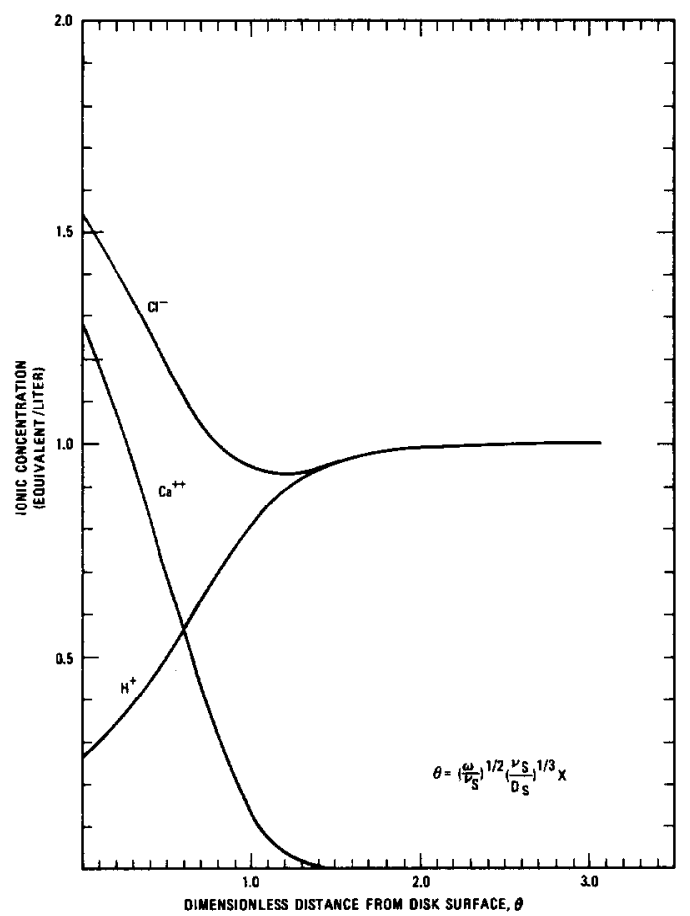

Fig. 2. Ionic concentrations in the boundary layer for run no. 243 performed at $1^{\circ} \mathrm{C}$ and $450 \mathrm{rpm}$.

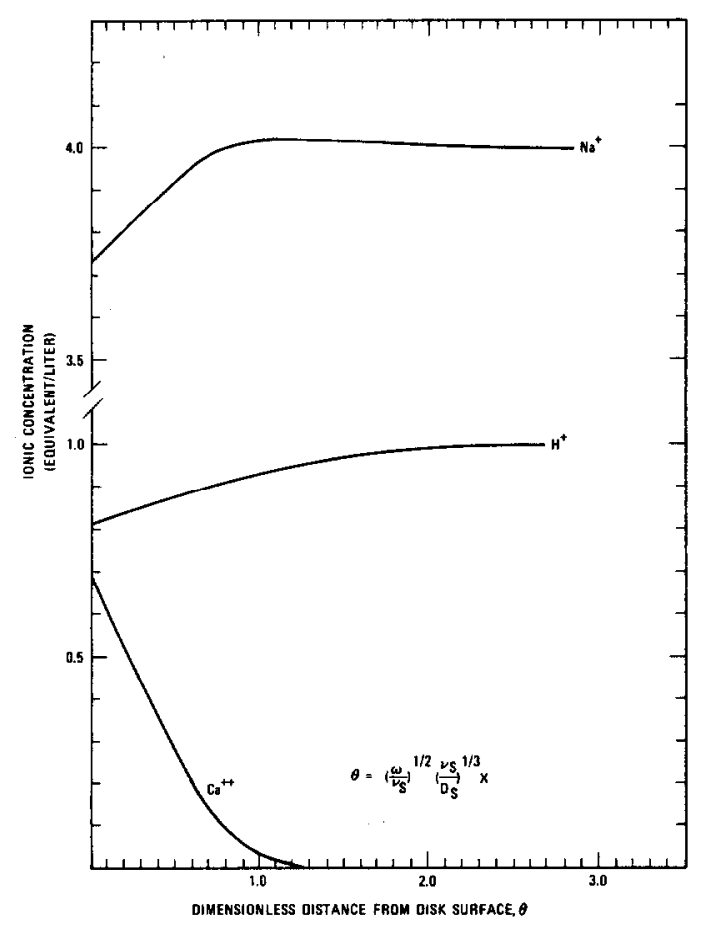

Fig. 3. Ionic concentration in the boundary layer for run no. 235 at $-15 \cdot 6^{\circ} \mathrm{C}$ and $500 \mathrm{rpm}$.

Calculated ternary diffusivities $D_{i j}$ for a representative $1^{\circ} \mathrm{C}$ experiment are shown in Fig. 4. The main variations of the $D_{i j}$ in the boundary layer can be explained in a qualitative manner by investigating the behavior of the $D_{i j}^{0}$ at infinite dilution. As the ratio of $C_{\mathrm{HCl}} / C_{\mathrm{CaCl}_{2}}$ approaches

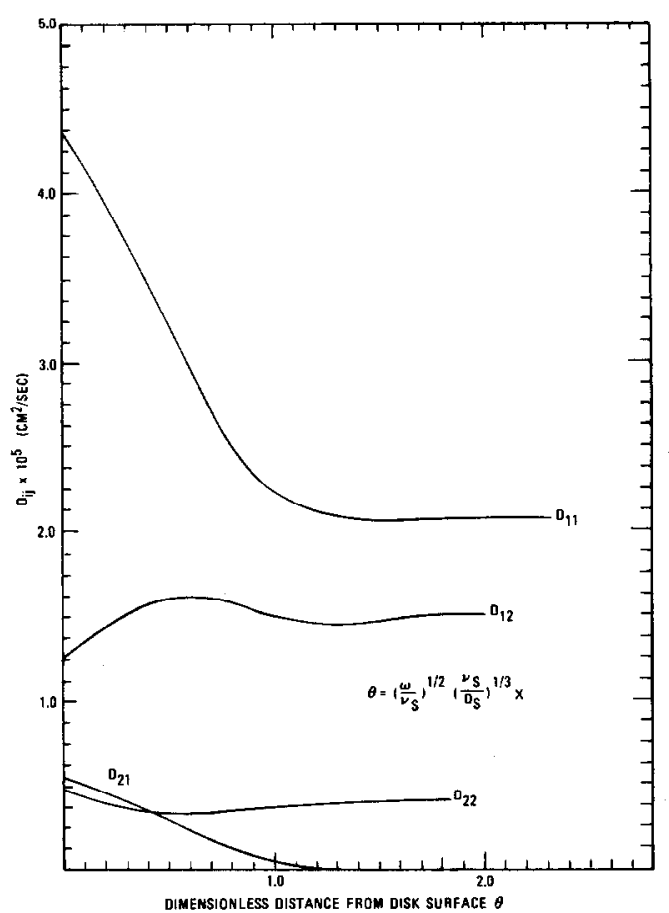

Fig. 4. Diffusivities in boundary layer for run 243 performed with $1 \mathrm{~N} \mathrm{HCl}$ at $1^{\circ} \mathrm{C}$ and $450 \mathrm{rpm}$.

zero, Eq. (31) becomes:

$$
\begin{aligned}
& D_{11}^{0}=\frac{R T}{F^{2}} \Lambda_{1}{ }^{0}=D_{H^{+}} \\
& D_{12}^{0}=0 \\
& D_{21}^{0}=\frac{R T}{2 F^{2}} \Lambda_{2}^{0} \frac{\Lambda_{3}^{0}-0 \cdot 5 \Lambda_{2}^{0}}{\Lambda_{2}^{0}+\Lambda_{3}{ }^{0}} \\
& D_{22}^{0}=\left[1 \cdot 5 \frac{R T}{F^{2}}\right] \frac{\Lambda_{2}^{0} \Lambda_{3}^{0}}{\Lambda_{2}^{0}+\Lambda_{3}^{0}}=D_{\mathrm{CaCl}_{2}}
\end{aligned}
$$

where

$D_{11}^{0}=$ diffusivity of $\mathrm{HCl}$ under the action of its own concentration gradient

$D_{22}^{0}=$ diffusivity of $\mathrm{HCl}$ under the action of the concentration gradient of $\mathrm{CaCl}_{2}$

$D_{21}^{0}=$ diffusivity of $\mathrm{CaCl}_{2}$ under the action of the concentration gradient of $\mathrm{HCl}$

$D_{22}^{0}=$ diffusivity of $\mathrm{CaCl}_{2}$ under the action of its own concentration gradient.

$D_{H}{ }^{+}$represents the limiting diffusivity of $\mathrm{H}^{+}$as it diffuses through the supporting electrolyte $\mathrm{CaCl}_{2}$. Since $D_{12}^{0}=0$, the $\mathrm{CaCl}_{2}$ gradient does not give rise to a $\mathrm{H}^{+}$flux. The diffusivity of the supporting electrolyte $D_{\mathrm{CaCl}_{2}}$ is identical with the one found for the binary system $\mathrm{CaCl}_{2}$ and $\mathrm{H}_{2} \mathrm{O}$. Similar expressions may be found when $\mathrm{HCl}$ acts as a supporting electrolyte (i.e. the ratio $C_{\mathrm{CaCl}_{2}} / C_{\mathrm{HCl}}$ approaches zero); for example:

$$
D_{\mathrm{1I}}^{0}=\left[\frac{2 R T}{F^{2}}\right] \frac{\Lambda_{1}^{0} \Lambda_{3}^{0}}{\Lambda_{1}^{0}+\Lambda_{3}{ }^{0}}=D_{\mathrm{HCl}}
$$

The ratio of $D_{\mathrm{H}^{+}} / D_{\mathrm{HCl}}$ indicates the extent that the dif- 
fusivity of the hydrogen ion may vary through the boundary layer:

$$
D_{\mathrm{H}^{+}} / D_{\mathrm{HCl}}=0.5\left(1+\Lambda_{1}{ }^{0} / \Lambda_{3}{ }^{0}\right) \cong 3 \cdot 2 \text { at } 1^{\circ} \mathrm{C} \text {. }
$$

In Fig. 4 we note that at small distances from the solid surface the value of $D_{11}$ is larger than the bulk value owing to the relative high $\mathrm{CaCl}_{2}$ concentration which acts as a supporting electrolyte. On the other hand, at the outer edge of the boundary layer, where the $\mathrm{CaCl}_{2}$ concentration is zero, $D_{11}$ becomes equal to $D_{\mathrm{HCl}}$. Due to the large equivalent conductivity of $\mathrm{H}^{+}$the effect of the other ions and their fluxes on $D_{11}$ is very strong. In the case where the rate of reaction of $\mathrm{HCl}$ with the calcite surface is fast compared to the mass transport rate, there will be an approximately three-fold variation of the diffusivity of $\mathrm{H}^{+}$ through the boundary layer. Similar observations can be made for the experiments at $-15 \cdot 6^{\circ} \mathrm{C}$.

Although the coupled convective diffusion equations describe the mass transport of acid to the rotating disk of calcite in an accurate and general manner, their solution is too cumbersome and difficult from a practical engineering viewpoint. The concentration of $\mathrm{HCl}$ at the solid-liquid interface was calculated for each of the dissolution rate experiments performed in the rotating disk apparatus and we may use this information to determine an effective diffusivity, $D_{\text {eff. }}$ The effective diffusivity may be calculated from the usual mass transfer correlation for a rotating disk (corrected for the varying viscosity and density by the Schuh correction factor):

$$
\begin{gathered}
N_{\mathrm{HCl}}=0.62\left(\frac{\mu_{b} \rho_{b}}{\mu_{s} \rho_{s}}\right)^{1 / 6} S c_{s}^{-2 / 3}\left(\nu_{s} \omega\right)^{1 / 2} \Delta C \\
=0.62\left(\frac{\mu_{b}}{\mu_{s}}\right)^{1 / 3} S c_{b}^{-2 / 3}\left(\nu_{b} \omega\right)^{1 / 2} \Delta C \\
S c=\nu / D_{\text {eff }}
\end{gathered}
$$

In Fig. 5, $D_{\text {eff }}$ is plotted as a function of bulk hydrochloric acid concentration. The dramatic effect of a supporting electrolyte $(\mathrm{NaCl})$ on $D_{\text {eff }}$ in the $-15.6^{\circ} \mathrm{C}$ experiments is clearly shown. The $\mathrm{NaCl}$ was added to make the ionic strength in the bulk acid solution approximately 5 gmoles/liter and the effect of the supporting electrolyte decreases rapidly as the bulk acid concentration increases.

The experiments performed at $1^{\circ} \mathrm{C}$ were analyzed in two different ways: (1) the activity coefficients were assumed to be independent of the electrolyte concentrations; (2) the activity coefficients were estimated by applying Harned's rule $[31,33]$. While there is little difference between these two methods at low bulk $\mathrm{HCl}$ concentrations, the difference does become significant at higher concentrations.

In Fig. 6 the dissolution rate of calcite is plotted as a function of the surface concentration of $\mathrm{HCl}$. The following rate expressions were found to describe the rate of dissolution:

$$
\begin{aligned}
& \text { at }-15.6^{\circ} \mathrm{C} \quad-r_{\mathrm{HCl}}=1.34 \times 10^{-6} \mathrm{C}_{\mathrm{HCl}}^{0.63}, \\
& \text { at } 1.0^{\circ} \mathrm{C} \text { (for } C_{\mathrm{HCl}}<1 \mathrm{gmole} / \text { liter) } \\
&-r_{\mathrm{HCl}}=8.8 \times 10^{-6} C_{\mathrm{HCl}}^{0.63} .
\end{aligned}
$$

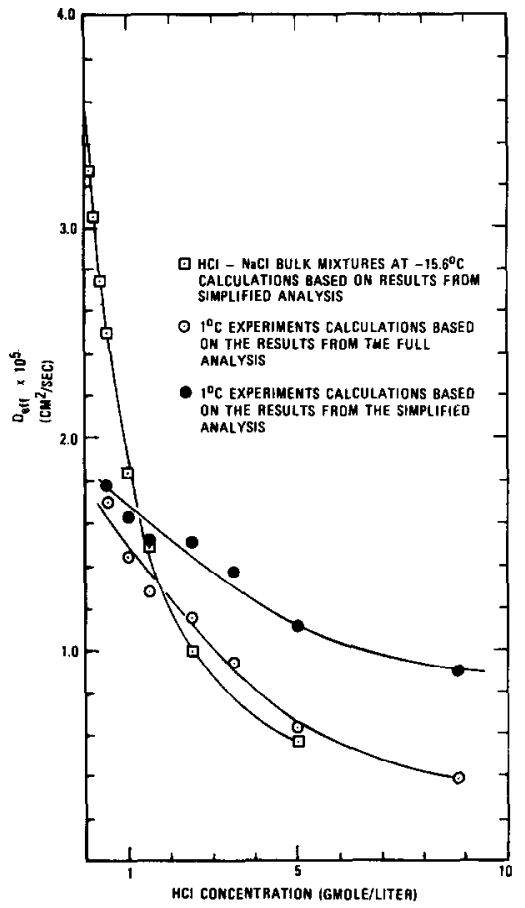

Fig. 5. Effective diffusivity of $\mathrm{HCl}$ as a function of bulk $\mathrm{HCl}$ concentration.

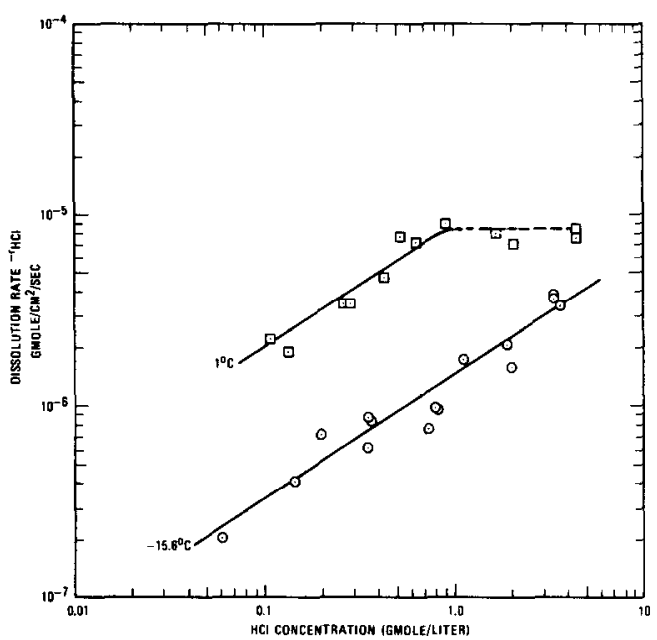

Fig. 6. Dissolution rate of calcite as a function of $\mathrm{HCl}$ concentration at surface.

The units of the surface concentration, $C_{\mathrm{HCl}}$, are gmole/liter and the dissolution rates are expressed in gmole $\mathrm{HCl} / \mathrm{cm}^{2} / \mathrm{sec}$. The activation energy for the surface reaction is $15 \mathrm{kcal} / \mathrm{gmole}$. No significant effect on the surface reaction rate can be noticed by the addition of $\mathrm{NaCl}$ to the acid solution.

At $1^{\circ} \mathrm{C}$ the rate of dissolution of calcite apparently becomes independent of the $\mathrm{HCl}$ concentration when $C_{\mathrm{HCl}}$ at the solid-liquid interface is larger than $1 \mathrm{gmole} /$ liter (this corresponds to 3.5 gmoles $\mathrm{HCl} / \mathrm{liter}$ in the bulk solution). This behavior may be explained by the following possible reasons. The derived mass fluxes and related approximations may not apply at very high ionic strengths (the order of $6-13$ moles $/ \mathrm{kg}$ solvent). For 
cxample, in the experiment where the concentration of $\mathrm{HCl}$ in the bulk solution was 3.5 gmoles/liter, the corresponding ionic strength at the solid-liquid interface was 6.1 molal.

It is also possible that the solubility of $\mathrm{CaCl}_{2}$ may have been exceeded in the boundary layer. Comparison of the calculated $\mathrm{HCl}$ and $\mathrm{CaCl}_{2}$ concentrations at the dissolving calcite surface with the solubility diagram for the ternary $\mathrm{HCl}-\mathrm{CaCl}_{2}-\mathrm{H}_{2} \mathrm{O}[35]$ shows that the solubility may have been exceeded in several of the experiments performed with a high bulk concentration of $\mathrm{HCl}$.

\section{ANALYSIS OF THE SURFACE REACTION RATE LAW}

In heterogeneous catalysis it is often found that a fluid-solid reaction can be described by the sequence: adsorption, surface reaction, and desorption. Although the calcite dissolution differs from a heterogeneous catalytic reaction by having a dissolving surface, the fractional power in the rate expression does suggest a reaction mechanism involving adsorption of the reactant $\mathrm{H}^{+}$on the solid surfaces. Electrokinetic measurements have shown [37] that calcite takes on a negative electrical potential in water and that the surface adsorbs positive ions from the solution. This mechanism was determined for the dissolution of dolomite $\mathrm{CaMg}\left(\mathrm{CO}_{3}\right)_{2}$ by hydrochloric acid [22], where the reaction of adsorbed $\mathrm{H}^{+}$with the solid surface was found to be the rate limiting step. In the crystal lattice the oxygen ion is much larger than $\mathrm{Ca}^{++}$, $\mathrm{Mg}^{++}$and $\mathrm{C}^{+4}$ in the carbonate ion. Therefore the surfaces of both calcite and dolomite will act as a packing of oxygen ions to the aqueous solution. Since the surfaces of these minerals are nearly identical and the surface reaction rates are so different (for a $1 \mathrm{~N} \mathrm{HCl}$ concentration at the solid-liquid interface calcite reacts approximately 650 times faster than dolomite at $25^{\circ} \mathrm{C}$ ) we may infer that the adsorption of $\mathrm{H}^{+}$with the solid surface is fast compared with the reaction of adsorbed $\mathrm{H}^{+}$with the solid surface. Desorption of products were shown not to limit the dissolution rate of dolomite and it is quite reasonable to consider this to be the case for calcite also. The surface of the calcite can be considered spatially heterogeneous (as was the case for dolomite) and a Freundlich adsorption isotherm may describe the adsorption of $\mathrm{H}^{+}$.

$$
C_{\mathrm{H}^{+} \mathrm{ads}}=K C_{\mathrm{HCl}}^{n} \text {. }
$$

If the reaction of adsorbed $\mathrm{H}^{+}$with the solid surface is the rate limiting step and the reaction is first order in adsorbed $\mathrm{H}^{+}$

$$
-r=k_{1} C_{\mathrm{H}^{+}} \text {ads }
$$

the rate law is obtained by substituting Eq. (38) into Eq. (39)

$$
-r=k_{1} K C_{\mathrm{HCl}}^{n}=\mathrm{kC}_{\mathrm{HCl}}^{\mathrm{n}} \text {. }
$$

From the theoretical derivation[38] of the Freundlich adsorption isotherm it follows that the exponent $n$ is the following function of the absolute temperature:

$$
n=\frac{R T}{(1-a T) X_{m}}
$$

Due to the fast reaction rate on the calcite surface we were only able to measure experimentally the rate law at $-15.6^{\circ}$ and $1{ }^{\circ} \mathrm{C}$; these temperatures are too close to evaluate the parameters $X_{m}$ and $a$ in Eq. (41). If in Eq. (41) the constant " $a$ " is set equal to zero, $X_{m}$ becomes equal to $0.8 \mathrm{kcal} / \mathrm{gmole}$. It should be noted that the "apparent" activation energy for the surface reaction rates of calcite and dolomite are both approximately $15 \mathrm{kcal} / \mathrm{gmoles}$. If the reaction is not first order in absorbed $\mathrm{H}^{+}$, the value of $X_{m}$ will change. However, the general conclusions reached in this paper and the rate law (based on the concentration of $\mathrm{H}^{+}$at the liquid-solid interface) will remain unchanged.

The minerals calcite and dolomite are nearly isostructural and therefore other properties than that of the lattice structure must exist which account for the large differences in measured surface reaction rates. The fact that the ionic radii of $\mathrm{Ca}^{++}$is 40 per cent larger than the ionic radii of $\mathrm{Mg}^{++}$may explain this difference. Fajen's [39] rules state that polarization (or covalency) of an ionic bond is increased when the cation is small and/or highly charged and the anion is large and/or highly charged. The $\mathrm{Mg}-\mathrm{O}$ bond will therefore be more polarized than the $\mathrm{Ca}-\mathrm{O}$ bond and due to the smaller bond length the dipole moment of the $\mathrm{Mg}-\mathrm{O}$ bond is also less. The observed diverse reaction rates of calcite and dolomite may therefore be explained by the differences in the character of bonding and the strength of the local charge field.

In the lattices of calcite and dolomite each cation is coordinated to six oxygen ions of six different carbonate groups, and each carbonate ion is coordinated to six cations. The release of a cation to the aqueous solution will be a complex process due to this complicated structure. Even though this is the case, some conclusions about the reaction mechanism can be reached. In the dissolution of calcite in $\mathrm{HCl}$, the breakage of the first of the six $\mathrm{Ca}-\mathrm{O}$ bonds may be the rate limiting step. Calcium bicarbonate is highly soluble and therefore the introduction of one $\mathrm{H}^{+}$into the lattice by breaking the first bond will increase the reactivity on the other bonds sufficiently, in which case the breakage of these bonds will not limit the rate of dissolution. Consequently, it is logical to assume the first order reaction rate dependence on adsorbed $\mathrm{H}^{+}$concentration in Eq. (39).

\section{SUMMARY}

The dissolution of calcite in hydrochloric acid was studied with the aid of a rotating disk system. Experiments were carried out under 800 psig and over a wide range of conditions. The acid concentration was varied between $0 \cdot 1$ and $9 \mathrm{~N} \mathrm{HCl}$, the disk rotation speed from $100-500 \mathrm{rpm}$, and runs were conducted at $-15 \cdot 6^{\circ}, 1^{\circ}$, and $25^{\circ} \mathrm{C}$. In some of the experiments sodium chloride was added to the acid solutions to lower the solution freezing point.

The multicomponent coupled ionic diffusive fluxes of reactants and products were defined in a fundamental manner and the concentration profiles of the ions in the boundary layer were determined numerically by integrating the system of coupled convective diffusion equations. 
The effect of the variable density, viscosity, and high mass fluxes on the fluid velocity in the boundary layer was taken into account.

The rate law for calcite dissolving in $\mathrm{HCl}$ is: $-r_{A}=k$ $C_{\mathrm{HCl}}^{0.63}$ where $k=1.34 \times 10^{-6}$ at $-15.6^{\circ} \mathrm{C}\left(-r_{\mathrm{a}}\right.$ in gmoles $\mathrm{HCl} / \mathrm{cm}^{2} / \mathrm{sec}$ and $C_{\mathrm{HCl}}$ is the surface concentration in gmoles/liter). The activation energy for the reaction is $15 \mathrm{kcal} / \mathrm{gmole}$. At $25^{\circ} \mathrm{C}$ the dissolution is nearly fully limited by mass transport even at the relative high rotation speed of $500 \mathrm{rpm}$. However, at $-15 \cdot 6^{\circ} \mathrm{C}$ both the mass transfer rate and the surface reaction rate were found to limit the rate of dissolution of calcite. Analysis of the experiments suggests that the reaction between hydrogen ion adsorbed on the surface and the solid calcite is rate limiting. The adsorption step can be described by a Freundlich adsorption isotherm which predicts a fractional power dependence of $\mathrm{HCl}$ concentration.

\section{NOTATION}

$a$ parameter in Freundlich adsorption isotherm

$A_{n+1}$ common anion of charge $z_{n+1}$

$C_{i}$ cation $i$ with charge $z_{i}$

$\hat{C}_{i}$ concentration of component $i ;$ gmoles $/ \mathrm{cm}^{3}$

$D_{\text {eff }}$ effective diffusivity, defined by Eq. (10)

$D_{i j}$ multicomponent diffusion coefficient, $\mathrm{cm}^{2} / \mathrm{sec}^{31}$

$D_{i j}^{0}$ multicomponent diffusivity based on a solventfixed [31] reference frame, $\mathrm{cm}^{2} / \mathrm{sec}$

$D_{s}$ value of $D_{11}$ at disk surface, $\mathrm{cm}^{2} / \mathrm{sec}$

$F$ Faraday's constant, 96,493 coulombs/equivalent

$H$ dimensionless axial velocity

$I$ total ionic strength

$I_{i}$ fractional ionic strength of electrolyte $i$

$J_{i}$ molar flux of species $i$ based on a mass fixed reference frame, gmoles $/ \mathrm{cm}^{2} / \mathrm{sec}$

$\left(J_{i}\right)_{0}$ molar flux of electrolyte $i$ relative to the solventfixed reference frame

$L_{i j}$ thermodynamic diffusion coefficient

$m_{i}$ mass flux of species $i$ based on a mass fixed reference frame, $\mathrm{g} / \mathrm{cm}^{2} / \mathrm{sec}$

$M$ molecular weight

$n$ number of solutes

$n_{i}$ mass flux of species $i$ based on a fixed reference frame, $\mathrm{g} / \mathrm{cm}^{2} \mathrm{sec}$

$N_{i}$ molar flux of species $i$ based on a fixed reference frame, gmoles $/ \mathrm{cm}^{2} / \mathrm{sec}$

$r_{i a}$ number of anions in one formula unit of electrolyte $i$

$r_{i c}$ number of cations $i$ in one formula unit of electrolyte $i$

$r_{\mathrm{HCl}}$ rate of reaction of $\mathrm{HCl}$, gmoles $/ \mathrm{cm}^{2} / \mathrm{sec}$

$R$ gas constant, $9 \cdot 3144$ Joules/gmole $/{ }^{\circ} \mathrm{K}$

Sc Schmidt number, dimensionless

$T$ absolute temperature, ${ }^{\circ} \mathrm{K}$

$\bar{V}_{j}$ partial molar volumes of species $j$

$V_{s}$ axial velocity at disk surface, $\mathrm{cm} / \mathrm{sec}$

$V_{x}$ axial mass average velocity, $\mathrm{cm} / \mathrm{sec}$

$W_{j}$ equivalent fraction of cation $j$ or ion $j$

$x$ axial distance, $\mathrm{cm}$

$X_{m}$ parameter in Freundlich adsorption isotherm

$y$ mean activity coefficient

$z$ species charge

\section{Greek symbols}

$\alpha_{i j}$ dimensionless diffusivity, $\alpha_{i j}=D_{i j} / D_{s}$

$\gamma_{i}$ mean activity coefficient of electrolyte $i$

$\gamma_{i(0)}$ mean activity coefficient of electrolyte $i$ in a binary aqueous solution

$\delta_{k j}$ Knonecker delta

$\theta$ dimensionless axial distance

$\mu$ solution viscosity, $\mathrm{g} / \mathrm{cm} / \mathrm{sec}$

$\nu$ kinematic viscosity, $\mathrm{cm}^{2} / \mathrm{sec}$

$\rho$ solution density, $\mathrm{g} / \mathrm{cm}^{3}$

$\rho_{i}$ mass concentration of species $i, \mathrm{~g} / \mathrm{cm}^{3}$

$\phi_{i}$ osmotic coefficient of $i$ in a binary aqueous solution

$\Lambda_{i}^{0}$ limiting equivalent electrical conductance of ion $i$

$\Psi$ chemical potential

$\omega$ disk rotation speed, $\mathrm{sec}^{-1}$

$\Omega_{j}$ equivalent strength of ion $j$

\section{Subscripts}

$b$ bulk property

$i$ species type such as $\mathrm{HCl}, \mathrm{CaCl}_{2}$ and $\mathrm{NaCl}$

$j$ species type such as $\mathrm{HCl}, \mathrm{CaCl}_{2}$ and $\mathrm{NaCl}$

0 solvent, $\mathrm{H}_{2} \mathrm{O}$

$s$ surface property

\section{REFERENCES}

[1] Langmuir D., Geochim Cosmochim. Acta 196832835.

[2] Nogami H. and Nagai T., Chem. Pharm. Bull (Tokyo) 1962 10728.

[3] Notari R. E. and Sokoloski T. D., J. Pharm. Sciences 196554 1500 .

[4] Weyl P. K., J. Geol. 195866163.

[5] Kaye C. A., J. Geol. 19576535.

[6] Curl R. L., Proc. 4th Int. Cong. Speology in Yugoslavia Vol. III, 12-16 Sept., 1965. Postojna-Ljublijana-Bubrovnik, Yugosiavia.

[7] Pytkowicz R. M., Oceanog. Mar. Bio. Ann. Rev. 1968683.

[8] Berner R. A. and Wilde P., Amer. J. Sci. 1972272826.

[9] Morse J. W. and Berner R. A., Amer. J. Sci. 1972272840.

[10] Hoak R. D., Lewis C. J. and Hodge W. W., I \& EC 194537 553.

[11] Armco Steel Corp., Project 12010 DUL, Water Quality Office, The Environmental Protection agency, Water Pollution Control Research Series, February 1971.

[12] Bituminous Coal Research, Inc., Project 14010 EIZ, Commonwealth of Pennsylvania, Dept. Mines \& Mineral Ind. and the Enviromental Protection Agency, Water Pollution Control Research Series, Part I, January 1970; Part II, December 1971.

[13] Van Poollen H. K. and Jargon J. R., The Oil \& Gas J. 196894 85.

[14] Nierode D. E. and Williams B. B., Soc. Petrol. Engr. J. 1971 406.

[15] Kern D. M., J. Chem. Ed. 19603714.

[16] Gortikov V. M. and Panteeva L. I., J. Gen. Chem. (USSR) 1937756.

[17] Terjesen S. G., Erga O., Thorsen G. and Ve A., Chem. Engr. Sci. 196114277.

[18] Dunlap P. M., US 3,042,610, July 3, 1962.

[19] Barron A. N., Hendrickson A. R., Wieland D. R., J. Petrol. Tech. 1962409.

[20] Williams B. B., Gidley J. L., Guin J. A. and Schechter R. S., Ind. Eng. Chem. Fun. 19709589.

[21] Boomer D. R., McCune C. C. and Fogler H. S., Rev. Scien. Instruments 197243225 .

[22] Lund K., Fogler H. S. and McCune C. C., Chem. Engr. Sci. 197328691.

[23] Cochran W. G., Proc. Camb. Phil. Soc. 193430365. 
[24] Emanuel A. S., The Effect of Variable Properties on Liquid Phase, Laminar Flow Mass Transfer, Ph.D. 1963, Univ. of Calif., Berkeley.

[25] Miller D. G., J. Phys. Chem. 195963570.

[26] Miller D. G., J. Phys. Chem. 1966702639.

[27] Miller D. G., J. Phys. Chem. 196771606.

[28] Miller D. G., J. Phys. Chem. 1967713588.

[29] Wendt R. R., J. Phys. Chem. 1965691227.

[30] Miller D. G., Am. J. Phys. 195624433.

[31] Lund K., Ph.D. Thesis, University of Michigan, 1974.

[32] Lietzke M. M. and O'Brien H. A. Jr., J. Phys. Chem. 196872 4409.

[33] Harned H. S. and Owen B. B., The Physical Chemistry of Electrolyte Solutions. ACS monograph series, 3rd Edition, Reinhold Pub. Co., New York 1958.

[34] Robinson R. A. and Stokes R. H., Electrolyte Solutions. Academic Press Inc., New York 1955.

[35] Filinovskii V. Y. and Kir'yanov V. A., Doklady Akademii Nauk SSSR 19641561412.

[36] Gmelins Handbuch Der Anorg. Chem. 8 Auflage. Verlag Chemii, Gmbh, Weinheim, Bergstrasse, West Germany, 1957.

[37] Doublas H. W. and Walker R. A., Trans. Faraday Soc. 1950 46559.

[38] Hayward D. O. and Trapnell B. M. W., Chemisorption, 2nd Edition. Butterworths, London 1964.

[39] Bloss F. D., Crystallography and Crystal Chemistry. Holt, Rinehart and Winston, New York, 1971.

[40] Carnahan B., Luther H. A. and Wilkes J. O., Applied Numerical Methods. Wiley, New York 1969.

\section{APPENDIX}

Summary of equations and method of solution

The mass transport of hydrochloric acid to the rotating disk of calcite is described by the following set of equations: $\sum_{i=1}^{n} \alpha_{i j} \frac{\mathrm{d}^{2} \tilde{C}_{i}}{\mathrm{~d} \theta^{2}}=H\left(\frac{\mathrm{d} \tilde{C}_{t}}{\mathrm{~d} \theta}-\tilde{C}_{i} \frac{\mathrm{d} \ln \rho}{\mathrm{d} \theta}\right)-\sum_{i=1}^{n} \frac{\mathrm{d} \alpha_{i j}}{\mathrm{~d} \theta} \frac{\mathrm{d} \tilde{C}_{j}}{\mathrm{~d} \theta} ; \quad i=1, \ldots, n$

where

$$
\begin{aligned}
H= & H_{s}+\left(\frac{\mu_{b} \rho_{b}}{\mu_{s} \rho_{s}}\right)^{1 / 2}\left(-0.51023 \theta^{2}+0.33333 \theta^{3} S c_{s}^{-2 / 3}\right. \\
& \left.-0.10265 \theta^{4} S c_{s}^{-2 / 3}+0.130 \theta^{5} / S c_{s}\right)
\end{aligned}
$$

and $\alpha_{t i}=D_{11} /\left(D_{11}\right)_{s}$. For the case of the quaternary system $\mathrm{HCl}-\mathrm{CaCl}_{2}-\mathrm{H}_{2} \mathrm{O}$ the mean activity coefficients are assumed to be constant and the diffusivities $D_{i j}^{\circ}$ (based on a solvent-fixed reference) are given by:

$$
D_{i j}^{0}=\frac{R T}{F^{2}} \frac{r_{i a} \Lambda_{i}^{0}}{r_{i a} \Lambda}\left(\delta_{y} \frac{\Lambda^{0}}{z_{l}}-W\left(\frac{\Lambda_{i}^{0}}{z_{l}}+\frac{\Lambda_{n+1}^{0}}{z_{n+1}}\right)\right)
$$

For the ternary system $\mathrm{HCl}-\mathrm{CaCl}_{2}-\mathrm{H}_{2} \mathrm{O}$ the diffusion coefficients based on a solvent-fixed reference frame are given in Table $\mathrm{Al}$. These expressions for the diffusivities were arrived at by combining Eqs. (26) and (27). The derivative of the logarithm of the mean activity coefficient $y_{1}$ (based on the molarity scale) with respect to the concentration of electrolyte $j$ is needed for the evaluation of the $D_{i j}^{0}$ of Table A1[31].

$$
\frac{\partial \ln y_{i}}{\partial C_{j}}=\frac{\bar{V}_{i}}{C_{0} \bar{V}_{0}}+\sum_{k=1}^{n} \frac{1000}{C_{0} M_{0}}\left(\delta_{k f}+\frac{C_{k} \bar{V}_{j}}{C_{0} V_{0}}\right) \frac{\partial \ln \gamma_{i}}{\partial m_{k}}
$$

$C_{j}$ is the concentration of species $j$ in gmoles/liter $\left(C_{1}=1000 \tilde{C}_{j}\right)$. The partial molar volumes $\bar{V}_{1}$ of $\mathrm{HCl}, \mathrm{CaCl}_{2}$ and $\mathrm{H}_{2} \mathrm{O}$ have been tabulated [31]. The mean activity coefficient $\gamma_{1}$ based on the molality scale was estimated by Harned's rule.

$$
\ln \gamma_{1}=\ln \gamma_{1(0)}-\Delta \phi \frac{I_{2}}{2 I}
$$

Table A1. Solvent fixed diffusion coefficients for the ternary $\mathrm{HCl}-\mathrm{CaCl}_{2}-\mathrm{H}_{2} \mathrm{O}$

$$
\begin{aligned}
& D_{11}^{0}=B\left\{\left[2 \Lambda_{1}^{0} \Lambda_{2}^{0} C_{2}+\dot{\Lambda_{1} \Lambda_{3}^{0}}\left(C_{1}+2 C_{2}\right)\right]\left[1+\frac{C_{1}}{C_{1}+2 C_{2}}+2 C_{1} \frac{\partial \ln y_{1}}{\partial C_{1}}\right\}\right. \\
& -\Lambda_{1}^{0} \Lambda_{2}^{0} c_{2}\left\{\frac{2 c_{1}}{c_{1}+2 C_{2}}+3 c_{1} \frac{\partial \ln y_{2}}{\partial C_{1}}\right\} \\
& D_{12}^{0}=B\left[\left[2 \Lambda_{1}^{0} A_{2}^{0} \frac{C_{1} C_{2}}{C_{1}+2 C_{2}}+A_{1}^{0} A_{3}^{0} C_{1}\right]\left[2+2\left(C_{1}+2 C_{2}\right) \frac{\partial \ln Y_{2}}{\partial C_{2}}\right]\right. \\
& \left.-\Lambda_{1} \Lambda_{2}^{\circ} c_{1}\left[1+\frac{4 c_{2}}{c_{1}+2 c_{2}}+3 c_{2} \frac{\partial \ln y_{2}}{\partial c_{2}}\right]\right\} \\
& D_{21}^{\circ}=B\left(\left[\Lambda_{1}^{0} \Lambda_{2}^{0} \frac{c_{1} c_{2}}{C_{1}+2 C_{2}}+\dot{\Lambda_{2} \dot{\Lambda}_{3}} c_{2}\right]\left[1+1.5\left(c_{1}+2 c_{2}\right) \frac{\partial \ln y_{2}}{\partial c_{1}}\right]\right. \\
& -A_{1}^{0} A_{2}^{0} c_{2}\left\{1+\frac{C_{1}}{c_{1}+2 C_{2}}+2 c_{1} \frac{\partial \ln y_{1}}{\partial C_{1}}\right\} \\
& D_{22}^{\dot{0}}=B\left(\left[0.5 \Lambda_{1}^{\circ} \Lambda_{2}^{0} C_{1}+0.5 \Lambda_{2}^{\circ} \Lambda_{3}^{\circ}\left(c_{1}+2 C_{2}\right)\right]\left[1+\frac{4 C_{2}}{C_{1}+2 C_{2}}+3 C_{2} \frac{\partial 1 n Y_{2}}{\partial C_{2}}\right]\right. \\
& \left.-\Lambda_{1}^{0} \Lambda_{2}^{0} c_{1}\left[\frac{2 c_{2}}{c_{1}+2 C_{2}}+2 c_{2} \frac{\partial \ln y_{1}}{\partial c_{2}}\right]\right\} \\
& \text { where } \\
& B=\frac{R T}{\left[C_{1}\left(A_{1}^{\circ}+A_{3}^{\circ}\right)+2 C_{2}\left(A_{2}^{\circ}+\Lambda_{3}^{0}\right)\right] F^{2}}
\end{aligned}
$$

$\mathrm{C}_{1}$ and $\mathrm{C}_{2}$ is the concentration of $\mathrm{HCl}$ and $\mathrm{CaCl}_{2}$ respectively, gmoles/21tor

$\Lambda_{1}^{\circ}, \Lambda_{2}^{\circ}$, and $\Lambda_{3}^{\circ}$ is the limiting equivalent conductivities of $\mathrm{H}^{+}, \mathrm{Ca}^{++}$, and $\mathrm{Cl}^{-}$respectively,

$\mathrm{cm}^{2} / \mathrm{ohm} / \mathrm{eguiv}$.

$y_{1}$ and $y_{2}$ is the mean activity coefficient of $\mathrm{HCl}$ and $\mathrm{CaCl}_{2}$ 


$$
\begin{gathered}
\ln \gamma_{2}=\ln \gamma_{2(0)}+\Delta \phi \frac{I_{1}}{I} \\
\Delta \phi=2 \phi_{1}-\phi_{2}-1
\end{gathered}
$$

where

$\gamma_{i(0)}=$ mean activity coefficient of electrolyte $i$ in a binary aqueous solution.

$I_{i}=$ fractional ionic strength of electrolyte $i$

$I=$ total ionic strength

$\phi_{t}=$ osmotic coefficient of electrolyte $i$ in a binary aqueous solution.

The mean activity coefficients and the osmotic coefficients of the electrolytes in the binary aqueous solutions have been tabulated for this system[31]. The solvent fixed diffusivities may be transformed to diffusivities based on the mass-fixed reference frame:

$$
D_{i j}=D_{l j}^{0}-\frac{\rho_{i}}{\rho} \sum_{k=1}^{n} D_{k j}^{0} \frac{\tilde{M}_{k}}{\tilde{M}_{i}} ; \quad i, j=1, \ldots, n
$$

The density and viscosity of the solution was estimated from binary data [31].

The boundary conditions for this set of coupled, ordinary differential equations (Eq. 9) are:

$$
\theta=0 \quad \sum_{j=1}^{n}\left(\alpha_{i j} \frac{\mathrm{d} \tilde{C}_{j}}{\mathrm{~d} \theta}\right)_{s}=-\left(\frac{J_{i} S c^{2 / 3}}{\sqrt{ }(\nu \omega)}\right) ; \quad i=1, \ldots, n
$$

where

$$
\begin{gathered}
\left(J_{i}\right)_{s}=N_{t}+50.046\left(\tilde{C}_{i} N_{\mathrm{HCl}} / \rho\right)_{s} ; \quad i=1, \ldots, n \\
\theta \rightarrow \infty \tilde{C}_{i}=\left(\tilde{C}_{i}\right)_{b} ; \quad i=1, \ldots, n
\end{gathered}
$$

The system of second order non-linear ordinary differential equations with boundary conditions which describes the mass transport represents a boundary value problem that may be solved most easily by reformulating the problem into an initial value problem. The concentration of the electrolytes at the solid-liquid interface $\{\tilde{C}\}_{s}$ was estimated, and the boundary conditions for the initial value problem are:

B.C.: $\theta=0$

$$
\begin{gathered}
\sum_{i=1}^{n}\left(\alpha_{i 1} \frac{\mathrm{d} \tilde{C}_{i}}{\mathrm{~d} \theta}\right)_{s}=-\left(\frac{J_{i} S c^{2 / 3}}{\sqrt{\nu \omega}}\right)_{s} ; i=1, \ldots, n \\
\tilde{C}_{i}=\left(\tilde{C}_{i}\right)_{s} ; \quad i=1, \ldots, n
\end{gathered}
$$

The system of differential equations with initial conditions was then integrated from $\theta=0$ by a fourth order Runge-Kutta until $\mathrm{d} \tilde{C}_{\mathrm{HCl}} / \mathrm{d} \theta$ was less than zero or $\theta$ was greater than 3.5.

The difference vector $\left\{\Delta C_{i}\right\}$ formed as the difference between the concentration vector at the end of the integration and the boundary value vector $\left\{C_{i}\right\}_{b}$ expresses the amount of misfit the initial value solution has as a solution to the boundary value problem. The solution will have converged as a solution to the boundary value problem when for a certain choice of $\left\{C_{i}\right\}_{s}=\left\{\beta_{i}\right\}$ the $\left\{\Delta C_{i}\right\}$ vector is identical with the null-vector $\left\{\Delta C_{i}\right\}$ is a function of $\left\{C_{i}\right\}_{s}$ and the roots $\left\{\beta_{i}\right\}$ may be determined by applying a multi-dimensional Newton-Raphson root-finding technique [40]:

$$
\left\{\Delta C_{i}\right\}_{s}=-\left[\frac{\partial\left(\Delta C_{i}\right)}{\partial\left(C_{j}\right)_{s}}\right]^{-1}\left\{\Delta C_{i}\right\}
$$

The partial derivative matrix

$$
\left[\frac{\partial\left(\Delta C_{i}\right)}{\partial\left(C_{j}\right)_{s}}\right]^{-1}
$$

was computed numerically, the value of the refined $\left\{C_{i}\right\}_{s}$ was then:

$$
\left.\left.\left\{C_{i}\right\}_{s} \leftrightarrow C_{i}\right\}_{s}+\Delta C_{i}\right\}_{s}
$$

and the solution of the initial value problem may be recalculated with the new value of the $\left\{C_{i}\right\}_{\text {s }}$ vector. The derivatives $\mathrm{d} \alpha_{i j} / \mathrm{d} \theta$ and $d \ln \rho / \mathrm{d} \theta$ were calculated using a backward difference formula. A cubic spline function interpolation and differentiation was used to evaluate $\partial \ln y_{k} / \partial C_{j}$ from tabular activity coefficient data, osmotic coefficient data, and partial molar volume data. The numerical solution to the boundary value problem usually converged after $4-5$ iterations. 